Original scientific paper

\title{
COMPREHENSIVE ANALYSIS OF COLD FORMED TUBE IN DRAWING PROCESS USING SIMULATION
}

\author{
Sutak, D.; Hatala, M.; Mital, D.; Duplakova, D.\# \& Botko, F. \\ Technical University of Kosice, Faculty of Manufacturing Technologies with a seat in Presov, \\ Bayerova 1, 08001 Prešov, Slovakia \\ E-Mail: darina.duplakova@tuke.sk (\#Corresponding author)
}

\begin{abstract}
Presented paper is focused on comparison of three types of steel for production of tubes with shaped internal surface for applications in energy producing industry. Simulations were performed in Deform3D software with usage of finite elements method. Steels 20MnCr5, C10 and 34CrNiMo6 were selected for simulations. Obtained results are showing deformation, stress, strain and temperature during cold drawing of tubes with shaped internal surface and also resulting comparison of three tested materials depending on the course of load during the forming process. As a conclusion of the presented research is comparison of presented three steels according to the simulation results. Presented paper has potential to increase knowledge base in the area of forming tubes with shaped internal surface. Obtained results can contribute to a proper selection of tool material, coatings and process set up for forming process of tubes with shaped internal surface.

(Received in October 2020, accepted in November 2020. This paper was with the authors 1 week for 1 revision.)
\end{abstract}

Key Words: Deform-3D, Mandrel, Cold Formed Tube, Drawing Process

\section{INTRODUCTION}

Individual industrial sectors are focusing especially on energy industry, which can be considered as a rapid developing and expanding area due to narrow cooperation and direct transfer of research and development knowledge into the manufacturing process. Research and development in above mentioned industry area is oriented on production process of final products or product with precise tolerance considering on final surface requirements [1-5]. From this point of view are finding reducing method of usage raw materials and energy efficiency even for small pieces manufacturing. General research described in presented article was realized by several researchers. Description of analysis process of cold drawing was realized based on fatigue tests in the article by Gerin et al., where was monitored behaviour of specifically designed tool on testing material [6]. Deformation simulations in the process of cold drawing technology for stainless steel platinum tubes using software environment Abaqus/Explicit was described by authors Linardon et al., who created simulation model with movable clamp [7]. Simulations using Finite Elements Method (FEM) were implemented also in research realization describing case studies of model creation for the cold drawing process using conical convergence bushing with inner tool [8]. Simulation analysis in environment of software Deform FE was realized research of relation between tube and flange. Connection was made by radially expanding tool segments in internal tube areas. Created model was monitored from the reason of procedures determinations for initial drawing processes and due to description of forming deformations at axial tube drawing [9]. Simulation and subsequent experimental verification were realized also research focused on description of continual tube cold drawing forming using CSPB process and description of parameters such as radius, stress, tension, gap and so on. Based on results was set assumptions about next supporting measures [10]. Software description of tube forming process are often using Lagrange or Lagrange-Euler methods, which is part of simulation software QForm 3D. Using methods used in simulation are described by steel forming problematics in the process of forming [11]. Simulations in 
research process of tube drawing offer determination of mechanical properties, initial structural changes, also heat transfer during manufacturing process using CFD simulation described in case study by Reggio et al. [12]. Problematic was researched also by several other researchers such as [13-30]. Based on above described is clear, that creation of prototypes in tube forming and tools to obtain tube with internal grooving have significant role in the research and development areas with direct implementation into practice. Above described overview confirm not only subjected research, but also importance of result implementations of predictions obtained by simulation analysis into selection of the most suitable material for drawn grooved tubes. Base idea of presented research formed from long term data collect from practice, as in energy industry are mostly used tubes with smooth surface despite the fact, that grooving tubes offer positive increase of devices performance. Detail analysis grooving tubes is clear the significant progress and contribution in energy industry and for processes of energy transfer. The main problem and reason of using smooth tubes is demanding process of manufacturing tubes and connected forming tools. In the fact of this was realized research, which is described in presented article using simulation analysis, which are basis for experimental verification. Original contribution of the paper consists of the behaviour prediction of the pipes during the pulling process, thus avoiding various errors and determining early precautions. Obtained knowledge from simulation predict properties and behaviour of testing materials, which create qualitative background in selection of the most suitable drawn grooved tubes. Since there is a very few research published from the problematic of tubes drawing and especially form the problematics of forming grooved tubes dealing simulations of process. Presented research is aimed to enhance knowledge to the description and optimization of the grooved tubes forming process.

\section{MATERIAL AND METHOD}

Usage of pipes has a great benefit in the energy industry such as heat exchangers with the benefit of reducing the load on the pumps. Grooved pipes have the role of a centrifugal force, where water is separated from the steam fraction. This is due to the displacement of water to the inner walls of the pipes. For right selection of the most suitable material drawn tubes is required inventory of the properties of those materials. The selection of three materials was subsequently simulated in the Deform-3D software program.

The first tested is steel C10, the products of which are made of bright steel. This steel is intended for general technical purposes. The second tested steel under the designation $20 \mathrm{MnCr} 5$ is considered as steel with improved machinability. The third tested material is steel 34CrNiMo6. This material is suitable for quenching and tempering. Standard EN 10263-4: 2001 is intended for various steel wires and rods intended for cold drawing or extrusion [31].

Table I: Chemical composition of used materials [32].

\begin{tabular}{|c|c|c|c|c|c|c|c|c|}
\hline Steel & $\mathrm{C}[\%]$ & $\mathrm{Si}[\%]$ & $\mathrm{Mn}[\%]$ & $\mathrm{P}[\%]$ & $\mathrm{S}[\%]$ & $\mathrm{Cr}[\%]$ & $\mathrm{Mo} \mathrm{[ \% ]}$ & $\mathrm{Ni}[\%]$ \\
\hline 20MnCr5 & $0.17-0.22$ & $\max .0 .4$ & $1.1-1.4$ & $\max .0 .025$ & $\max .0 .035$ & $1-1.3$ & - & - \\
\hline C10 & $0.07-0.13$ & $\max .0 .4$ & $0.3-0.6$ & $\max .0 .045$ & $\max .0 .045$ & - & - & - \\
\hline 34CrNiMo6 & $0.3-0.38$ & $\max .0 .4$ & $0.5-0.8$ & $\max .0 .025$ & $\max .0 .035$ & $1.3-1.7$ & $0.15-0.3$ & $1.3-1.7$ \\
\hline
\end{tabular}

During the first step of carrying out experiment, it is necessary to determine and set the initial values. These are entered in Deform-3D software, especially for tube, die and mandrel. Specified parameters will provide a clear record of simulation measurements, with the help of which we can better determine the material that is more suitable for us.

The principle of the tubes drawing consists in reducing the diameter by means of a die and a grooving mandrel (Fig. 1). The pipe is compressed at one end and drawn through the dies. 
The die usually has a conical cross-sectional shape, which task is to change the resulting tube diameter. The mandrel is intended to reduce and change the shape of the inner diameter of the tube. The mandrel is free to rotate depending on the bite in the inner walls of the tubes (socalled groove appearance). A bearing located on the opposite side of the mandrel has the task of facilitating a smoother rotation of the spline.

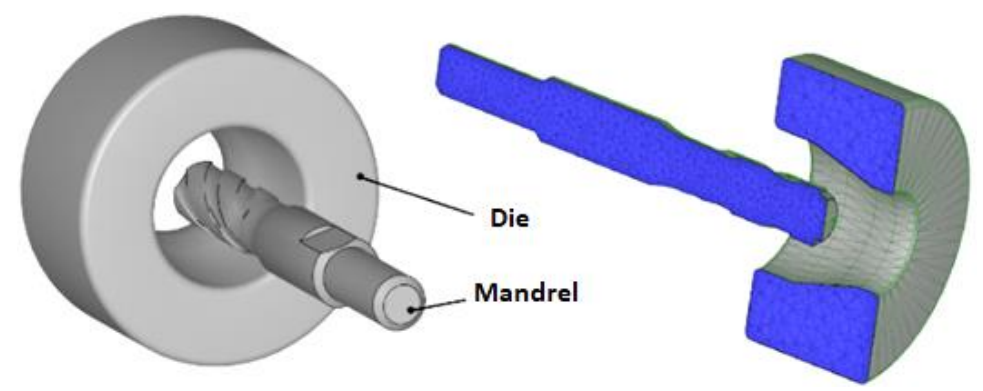

Figure 1: Model used for drawing tubes cold.

\section{RESULTS AND DISCUSSION}

\subsection{Simulation analysis}

After the determination of input data to simulation software, there was carried out the experiments. The first experiment consisted of $\mathrm{C} 10$ steel simulation and data analysis. The analysis showing the deformation of the tube has one of the main positions in the area of conditions, which helps us to determine the accuracy of such simulations.
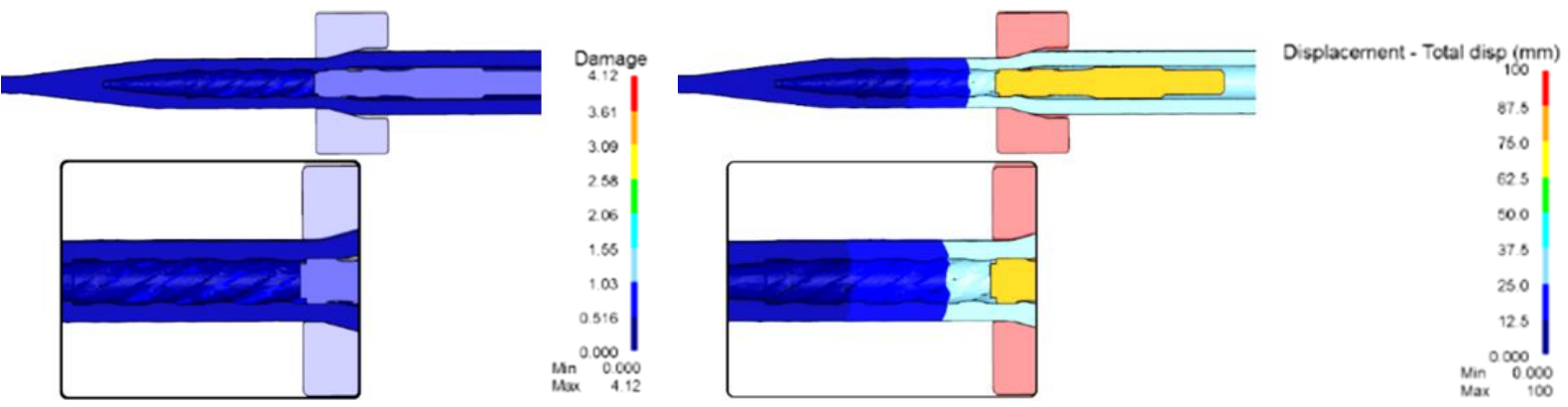

Figure 2: Simulation of deformation (left) and total displacement (right) - C10.

Analysis consists of the deformed tube composition, grooving mandrel and die. If the material used is properly designed, there is no major damage to the tube. It was in the proposal of the C10 material that the damage that was greatest in one of the materials tested occurred. The greatest deformation was in the area of the inner grooves of the tube. In this area, it was a measured value of 1.03, which was still at the optimal level compared to the other measurements. When the outer diameter of the pipe was reduced, deformations of 0.516 occurred. The same value was also measured to reduce the inner diameter before grooving. The right side of Fig. 2 consists of simulations of the resulting analysis of the total displacement under the influence of the drawn tube used through the forming die and the grooving mandrel. The resulting value is, of course, different than during the simulation. This value varies depending on the length of the drawn tube and the change in the reduced diameter. Fig. 3 shows the simulation of the resultant analysis recorded on the length of $154 \mathrm{~mm}$. At the beginning before drawing the tube, the total extrusion was set to $0 \mathrm{~mm}$. During the drawing and reducing the tube, the pipe length of $195 \mathrm{~mm}$ was extended by $50 \mathrm{~mm}$. This course of the resulting analysis was the same for the other two materials tested. 

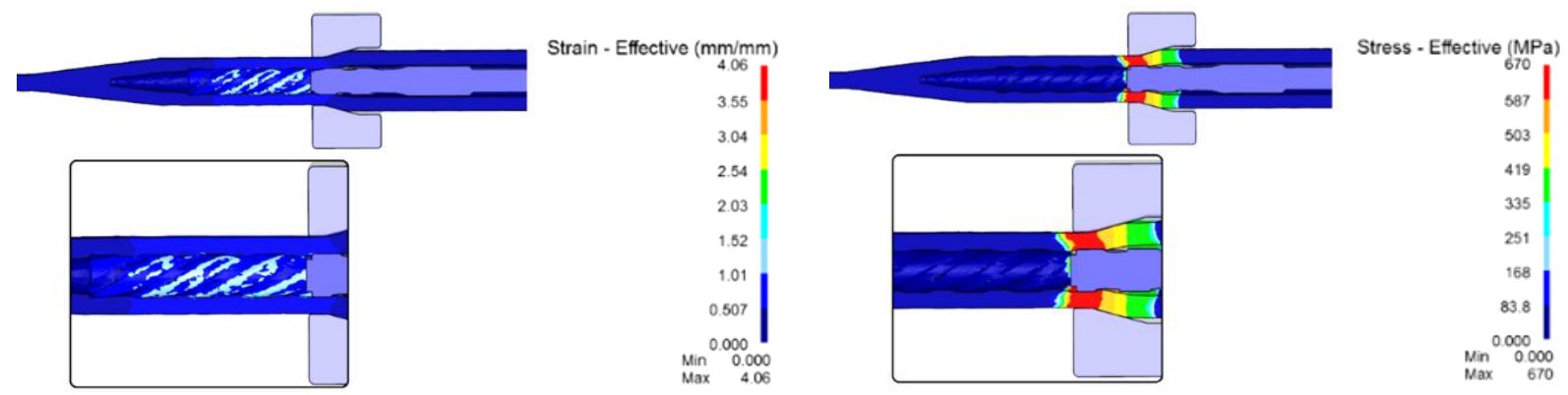

Figure 3: Simulation of the strain effective (left) and stress effective (right) $-\mathrm{C} 10$.

To analyse the strain efficiency, can be noticed that the direction of drawing the tube through a die to reduce the diameter. While reducing the tube at the outside diameter, a strain effective was 0.507 . The inner diameter area was recorded at 1.01. Value 2.03 the points of deformation and grooving with the assistance of a mandrel. This value was also the highest measured value. In the stress effective analysis, a die was used to reduce the diameter and grooving mandrel. Looking at the detail in the figure, it is possible to see more precisely the area of the exact points of efficiency of the mechanical stress. The greatest mechanical stress value was $670 \mathrm{MPa}$. This was located on the outside diameter (the area between the die and the drawn / formed tube) changed, as well as the internal grooving process. In places where only the beginning of changes in the outer diameter occurred, the measured value was $503 \mathrm{MPa}$. At the places where the drawn tube had first obtained its final shape, the measured value was $419 \mathrm{MPa}$. It gradually decreased to $83.8 \mathrm{MPa}$, which was also a constant value.
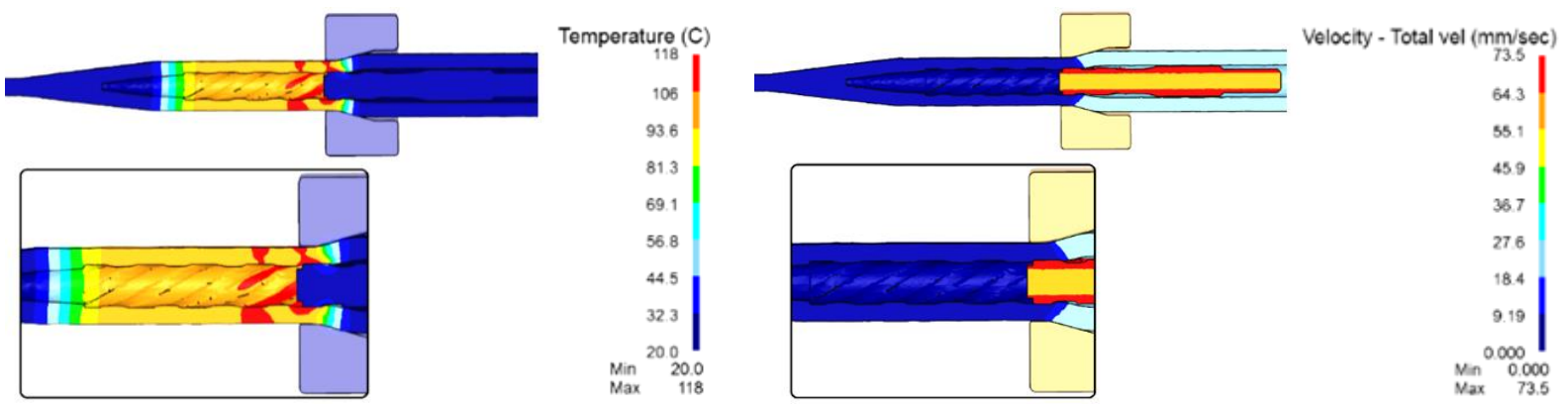

Figure 4: Simulation of the temperature (left) and velocity (right) - C10.

The temperature analysis (Fig. 4) is another significant simulation process. The initial temperature for simulation was set to $20^{\circ} \mathrm{C}$. This is a temperature that is also set as the normal operating temperature. During the simulation of tube reduction and forming, the maximum temperature was $118^{\circ} \mathrm{C}$. This temperature was recorded just in places of reduced pipe diameter and at the same time the formation of grooves in the inner walls of the tube. Subsequent drawing of the tube decreases the temperature to $93.6{ }^{\circ} \mathrm{C}$. With the "support" of temperature analysis can be determined the needs for the use coatings. The purpose of coatings is to keep the temperature of the pipes at an optimum and constant temperature, but also to make the passage through the die smoother. The latest analysis showing the overall velocity simulation during the extension of the tube is shown in Fig. 4 on the right side. The tube is also elongated during this process. For this measurement in the simulation, a value of $100 \mathrm{~mm} / \mathrm{sec}$ was measured. This is a constant value (constant) during the drawing process. This process was identical in the analysis of all three materials tested.

When analysing the second material, the simulation was carried out using the same measurements as for the first material. Initial resp. input values were entered under the same conditions as for the first material selected. In the first simulation analysis (Fig. 5), the damage simulation was higher than in the second material design. The maximum damage was measured 
at 0.910 . The area of the greatest deformation was located at the points of the internal grooving, namely the area of the internal edges of the grooves. There was a slight deformation of 0.455 between the inner and outer diameter of the tube. This deformation was caused by the reduction of the tube diameter from the initial to the desired one.
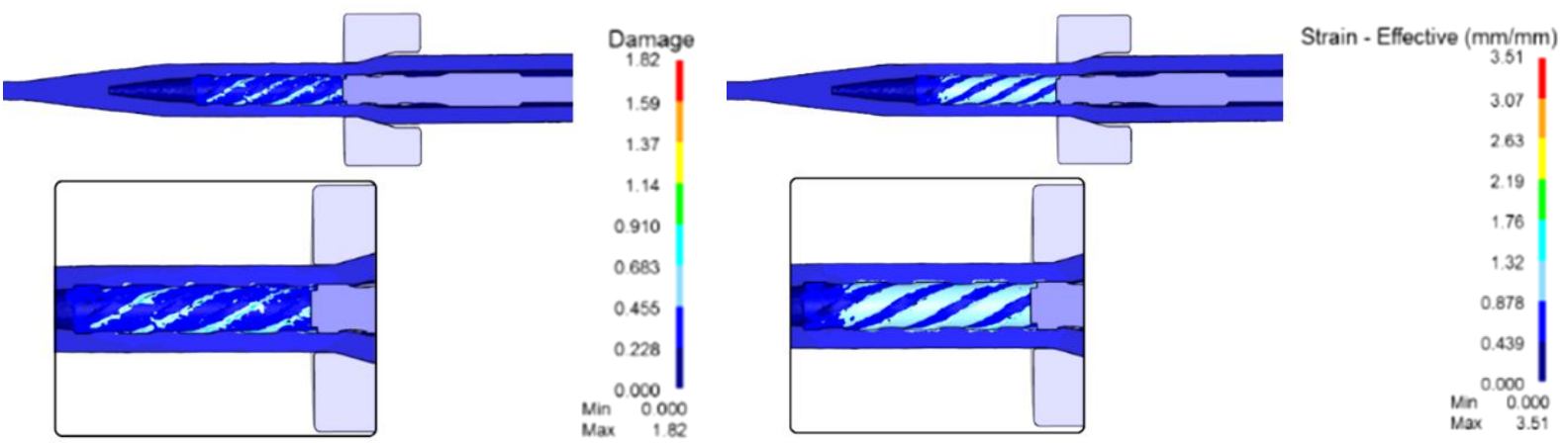

Figure 5: Deformation simulation (left) and strain effective (right) $-20 \mathrm{MnCr} 5$.

During the simulation of the strain-effective a measured maximum value of 1.76 was recorded. This was located on the entire surface of the internal grooves which were pressed into the tube material by means of a grooved mandrel. In the area of the inner reduced diameter, the strain effective was measured at 0.878 . Strain after drawing and reducing was the same around 0.439 .

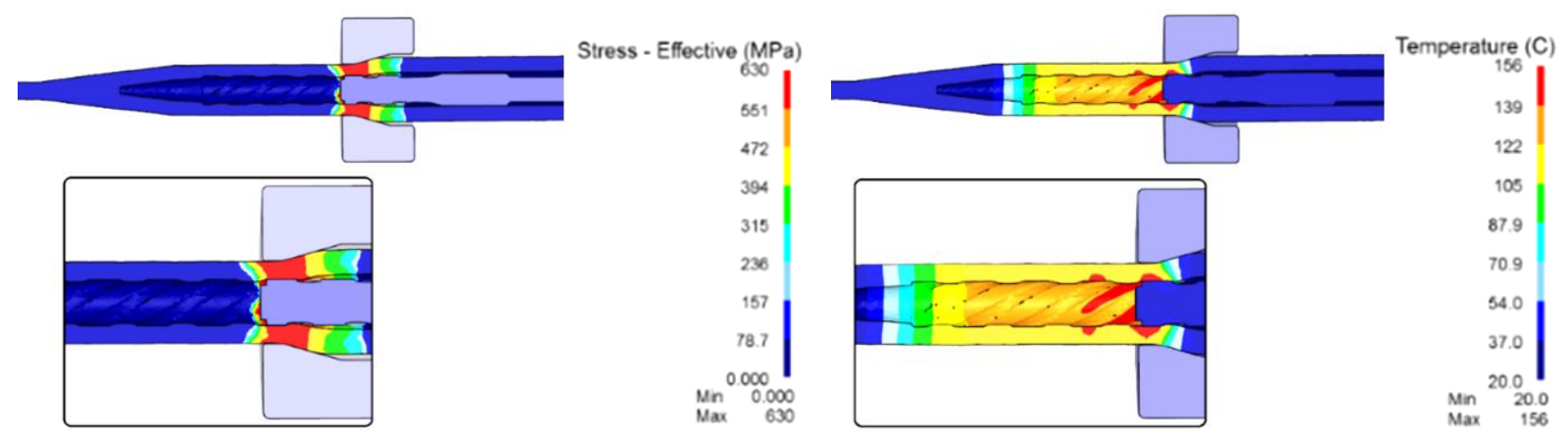

Figure 6: Stress effective simulation (left) and temperature simulation (right) $-20 \mathrm{MnCr}$.

When analysing the stress effective (Fig. 6), the maximum value recorded was lower in comparison to the first material tested (C10). For the second proposed material, it was recorded at a maximum value of $630 \mathrm{MPa}$. This was at the point where the tube diameter was reduced through the die and at the same time the grooves were formed in the inside diameter of the tube. Although the area of mechanical stress at reduction is greater than the first material tested, it is still a mechanical stress that is lower by $40 \mathrm{MPa}$. The area of initial diameter forming (the beginning of diameter reduction to the desired diameter) reached the mechanical stress effective of $472 \mathrm{MPa}$. In the case of temperature analysis also, the initial temperature (i.e., prior to the simulation) is $20^{\circ} \mathrm{C}$. Since this is the same test as the first material, the same input values need to be determined. The resulting analysis shows the region of the highest recorded temperature on value $156^{\circ} \mathrm{C}$. This is the area where internal grooving was created along with reducing the diameter. The inner grooves of the tube were formed by pressing the mandrel into the tube wall, which resulted in a temperature rise in these places. In the area of reduction of the diameter to the desired value, $122{ }^{\circ} \mathrm{C}$ was measured. This was then stabilized at $105^{\circ} \mathrm{C}$. Compared to the first material $(\mathrm{C} 10)$, the latter has a higher temperature in the drawing process.

The resulting analysis of the third material was also carried out under the same conditions as in the first and second cases. The input values for all three materials were identical, precisely 
because of the test to select the most suitable material for the drawn tube. As in the first and second case of the simulation, in the third case, the damage simulation was performed as first step. Fig. 7 presents area of greatest damage just at the internal grooving points. More precisely, it is a recorded value of 0.860 , which is only in the area of the edges located in the indented groove into the pipe material. On the whole surface of the indented groove the area of damage is lower, namely 0.688 . In the process of reducing the diameter to the desired, tube damage was recorded at 0.344. In this test, it is the damage of the tube that is most advantageous for the third material being tested.
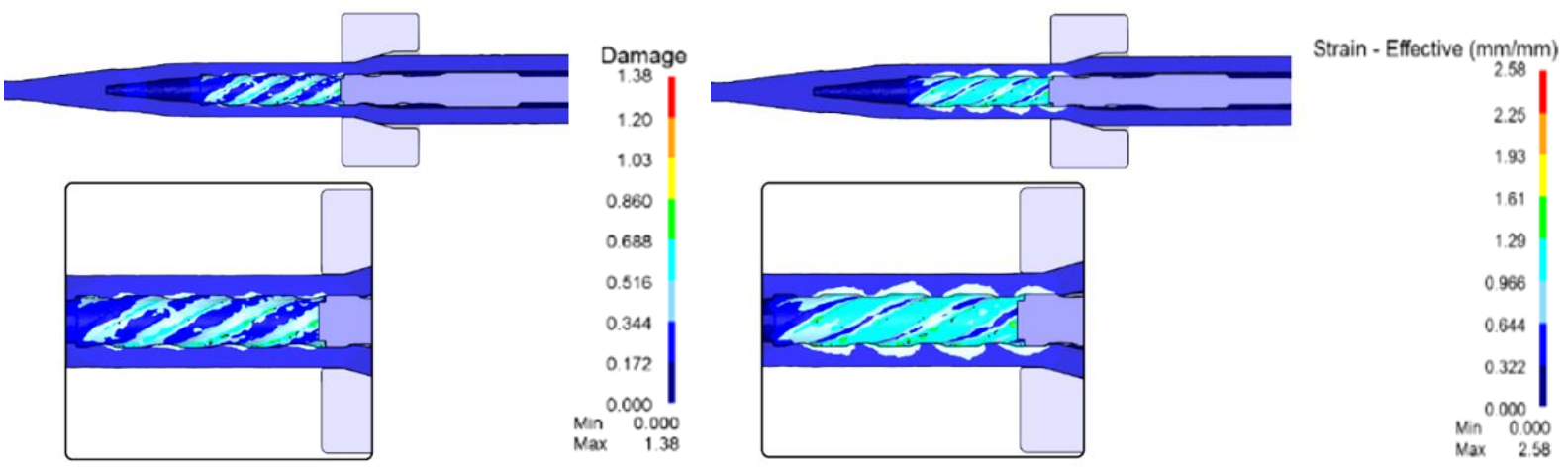

Figure 7: Deformation simulation (left) and strain effective (right) - 34CrNiMo6.

During the analysis of strain effective, the maximum and minimum locations (areas) were monitoring to obtain process behaviour. The maximum strain was recorded at 1.61. That was in the area along the inner perimeter of the tube. From the internal grooves to the external diameter through the material, the strain decreased. From the value just behind the inner groove towards the outer diameter, a value of 0.644 was recorded. It was only 0.322 on the outside surface. Based on to this analysis we can see the difference of the proposed materials.

The efficiency of mechanical stress was one of the main tasks in simulation. As a result of analysis, the maximum obtained value of stress was $543 \mathrm{MPa}$. It was precisely the place of the greatest reduction in diameter along with the production of the internal groove. It is the place where the diameter is reduced and the grooves are formed with the help of the mandrel, which is most often and most loaded in the analysis of damage, stress efficiency, mechanical stress and temperature analysis. During gradual drawing the mechanical stress decreases to a constant value of $90.5 \mathrm{MPa}$ from the point of reduction of the tube diameter through the die.

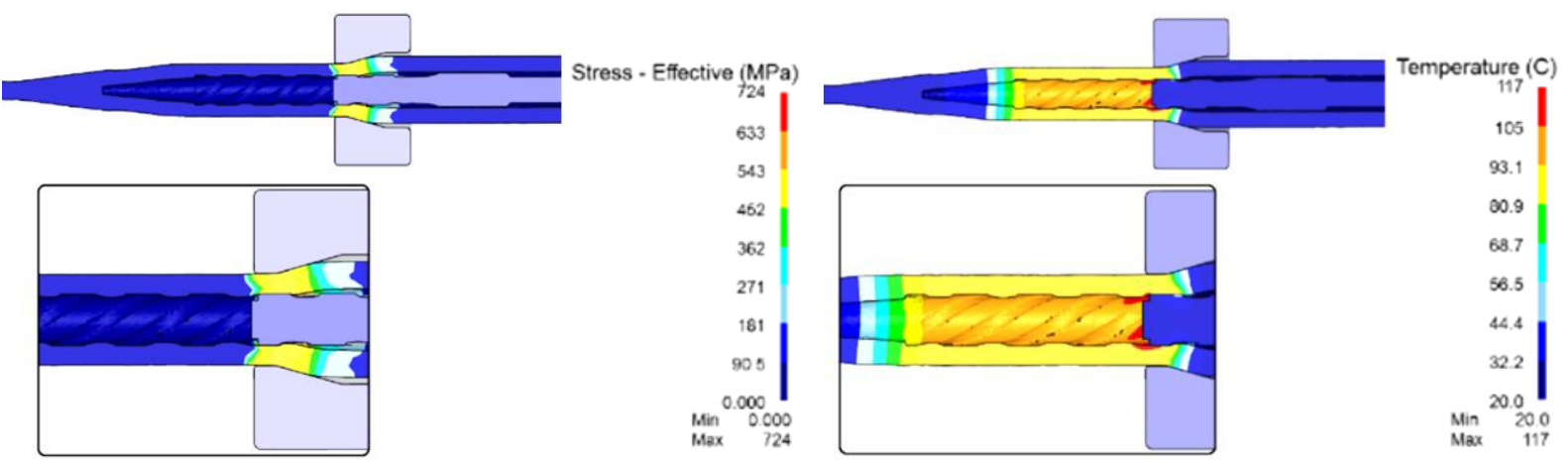

Figure 8: Simulation of the temperature (left) and velocity (right) - 34CrNiMo6.

The thermal analysis simulation (Fig. 8) is one of the main factors for the subsequent selection of the right coating. This is necessary for smoother and trouble-free running through the dies and mandrels. Just as the previous temperature simulation so the maximum temperature of $117^{\circ} \mathrm{C}$ was recorded just when the groove was formed by the mandrel. Although the temperature range is identical to the first and second material, the heating temperature is the 
lowest. At the reduction site, the temperature was recorded at $93.1^{\circ} \mathrm{C}$. Gradually moving away from the diameter reduction site, the material temperature decreased to value $80.9^{\circ} \mathrm{C}$.

\subsection{Analysis of obtained results}

For all tested materials, according to the results of the simulation, there were drawn shapes of the curves - dependence of load on time, load on stroke, load on step.

The first graph (Fig. 9) consisting of a graph of the load (y-axis) of the drawn pipe versus time (x-axis). This is a course where the beginning of the drawn tube through the die begins to reduce the tube profile to the required diameter. At the same time, the first penetration of the mandrel into the tube material is recorded. This rise is recorded in the graph, where the time is recorded $0.26 \mathrm{sec}$. Currently there was a rapid increase in the load of $151.8 \mathrm{kN}$. After a time of $1.53 \mathrm{sec}$, the program determined the average load of the overall analysis at $169.11 \mathrm{kN}$. In the second case, this is solved as a dependence of the stroke (x-axis) of the drawn tube to the load (y-axis) course throughout the simulation period. The graph also shows the first run of the forming tool into the tube material. It is a thread grooving. The first bite into the material was at a stroke of $24 \mathrm{~mm}$ and a load of $151.8 \mathrm{kN}$. After the overall analysis, the program determined the average load of $169.11 \mathrm{kN}$ at $100 \mathrm{~mm}$ stroke. The third graph is a representation of step (x-axis) versus load (y-axis) for the first C10 material tested. The first run of the forming tool under a load of $151.8 \mathrm{kN}$ was measured by the program at the step 240 . The course of the whole analysis shows that the course is chaotic during the entire rotation of the forming tool around its longitude axis. After one turn, the load course stabilizes. The resulting post-stabilization analysis were determined at a load of $169.11 \mathrm{kN}$ at an average step value of 1000 .

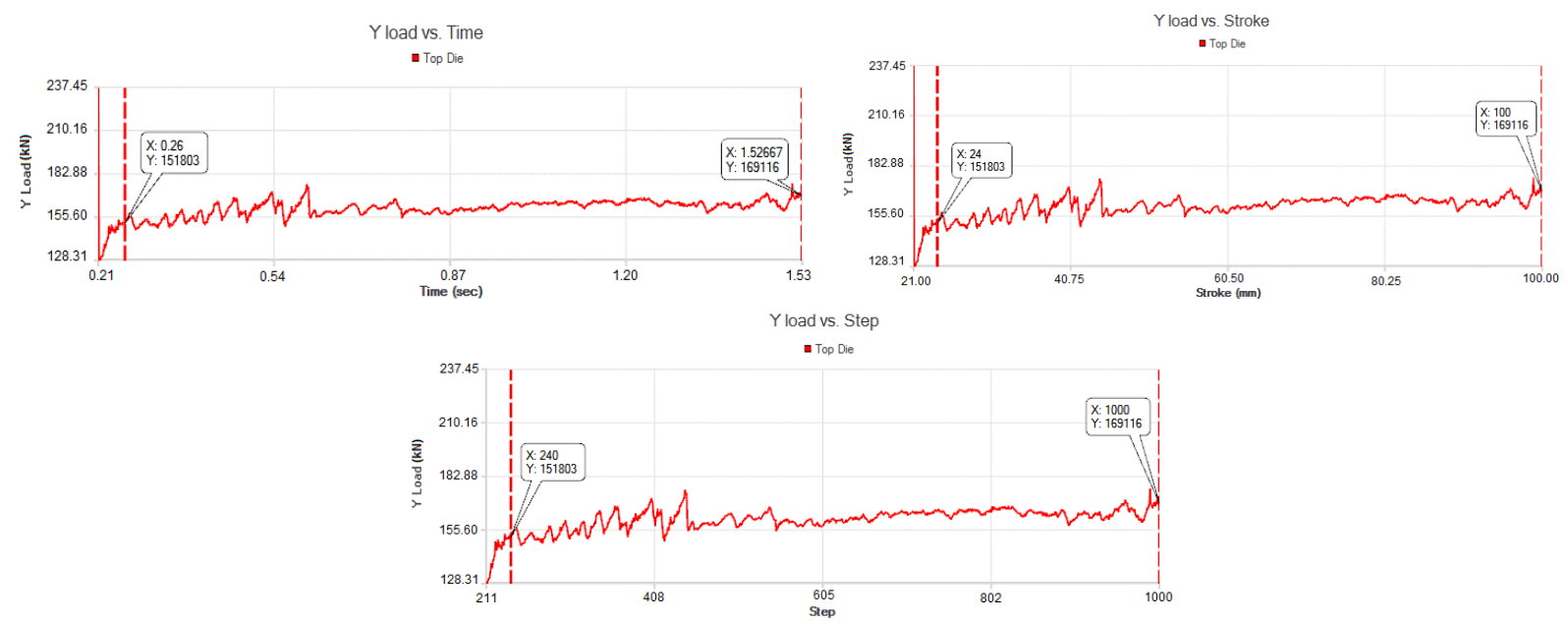

Figure 9: Shapes of the curves - C10.

The graphical analysis of the second material (Fig. 10) points to the drawing pattern from the first lead of the mandrel to the result which averaged as optimal. As with the first material, the second tool tested first simulation was at $0.26 \mathrm{sec}$. During this start-up there was a high load increase of up to $160.8 \mathrm{kN}$. Subsequently, the drawing already after start-up began to slightly optimize the load ranging from $160 \mathrm{kN}$ to $182 \mathrm{kN}$. The program therefore determined at $1.53 \mathrm{sec}$. average load value of $171.1 \mathrm{kN}$. The second graph (Y vs. Stroke) shows the overall progress from the start of the drawing to the optimum value which is averaged at the end by the program. The first recorded value was when the forming tool was first pressed into the tube material. This value was recorded at a stroke of $24 \mathrm{~mm}$ where the load was $160.8 \mathrm{kN}$. Gradual drawing (diameter reduction) and groove formation was subsequently recorded as optimized diameter. The resulting $100 \mathrm{~mm}$ stroke was a load of $171.1 \mathrm{kN}$. The results of graphical interpretation (load vs. step) the step value was in the range of $161 \mathrm{kN}$ to $181 \mathrm{kN}$. After 
measuring, the program determined the optimum load value of $171.08 \mathrm{kN}$. The aim was to determine the optimal value after step 1000.

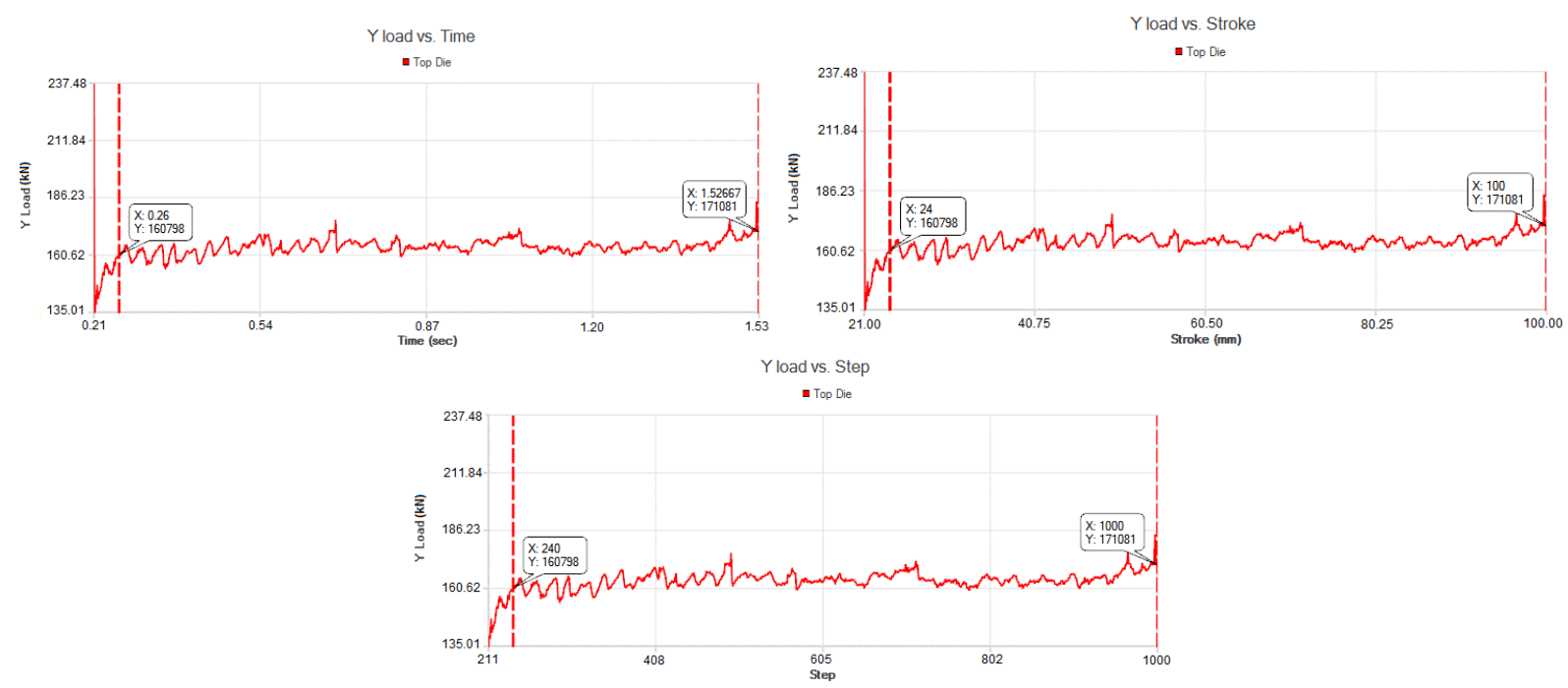

Figure 10: Shapes of the curves $-20 \mathrm{MnCr} 5$.

As with the first and second material, the analysis of the third material also shows the drawing process of the tube with the aid of a die and a forming mandrel (Fig. 11). Graphical interpretation of load vs. time is the analysis from the first run of the forming mandrel into the inner walls of the tube to the final one, which was determined to be optimal for the material. At the first start-up at $0.26 \mathrm{sec}$. load increased to $145.18 \mathrm{kN}$. After the first start-up, the load ranged from $134 \mathrm{kN}$ to $158 \mathrm{kN}$. For this range, the program evaluated at $1.53 \mathrm{sec}$. average load value of $146 \mathrm{kN}$. During the simulation was also investigated the load vs. stroke. Results was recorded throughout the drawing time through the die and mandrel. The first record was determined at the first tool entry into the material at a stroke of $24 \mathrm{~mm}$. A load of $145.18 \mathrm{kN}$ was recorded at this point. Subsequent drawing of the tube through the die to form the internal groove at a stroke of $100 \mathrm{~mm}$ was determined by the program with an optimum load of $146 \mathrm{kN}$. This optimum value comprised between $136 \mathrm{kN}$ and $156 \mathrm{kN}$.

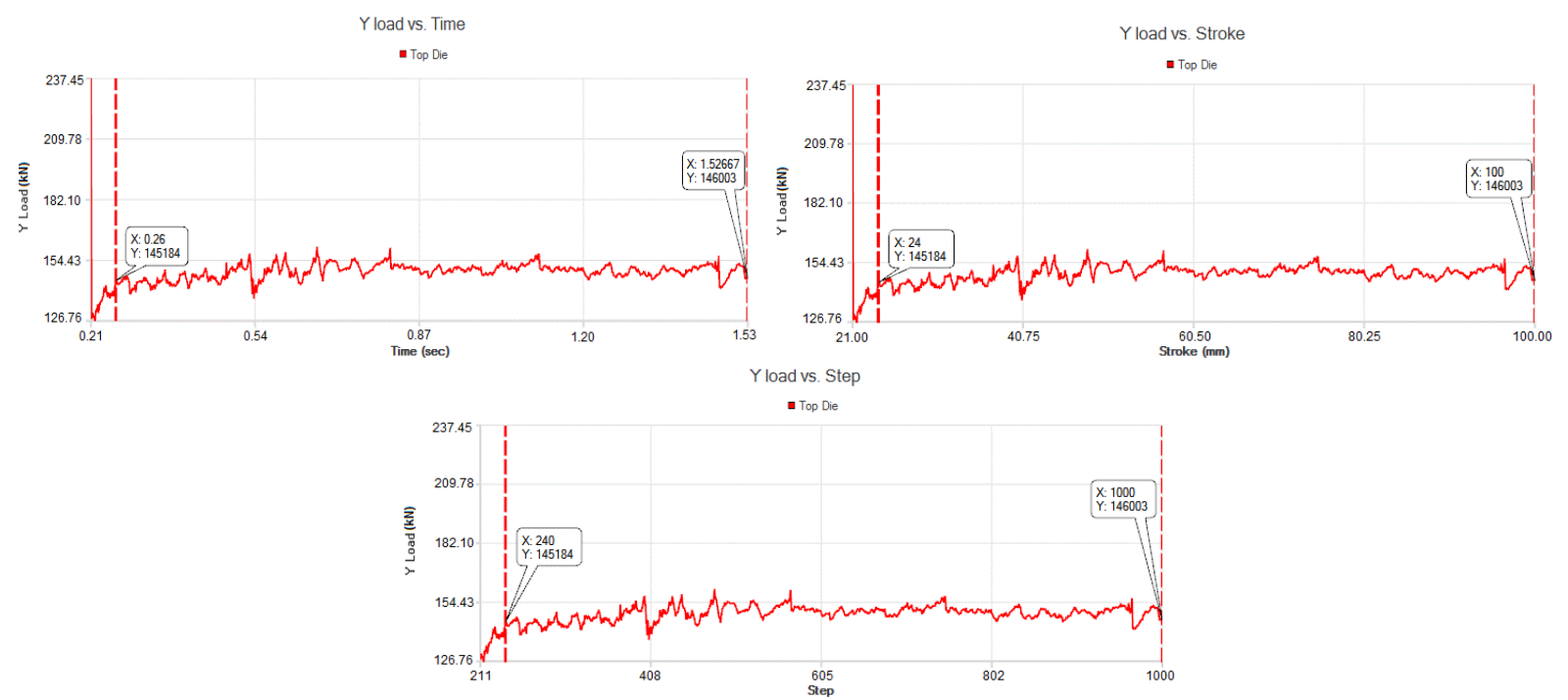

Figure 11: Shapes of the curves - 34CrNiMo6. 


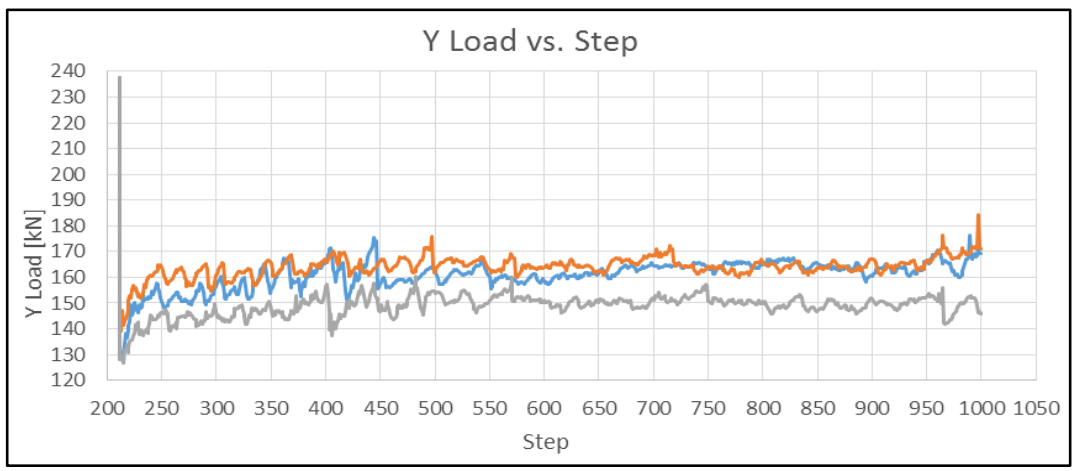

Figure 12: Shapes of the curves - load vs. step (red - C10; blue - 20MnCr5; grey - 34CrNiMo6).

In comprehensive evaluation of obtained results (Fig. 12), for C10, load was in the range of $159 \mathrm{kN}$ to $179 \mathrm{kN}$. The second test material (20MnCr5) was in the range from $161 \mathrm{kN}$ to $181 \mathrm{kN}$. The third test material (34CrNiMo6) ranged from $136 \mathrm{kN}$ to $156 \mathrm{kN}$. At step 400 (after the first tool start), the program recorded the lowest load of the third material value $138 \mathrm{kN}$. For the second material, this was a $168 \mathrm{kN}$ load. The first material at step 400 recorded the same load as the second material $(168 \mathrm{kN})$. The variation in the span of the boundaries for loading the materials while drawing the tube through the die was sufficient for the correct material selection.

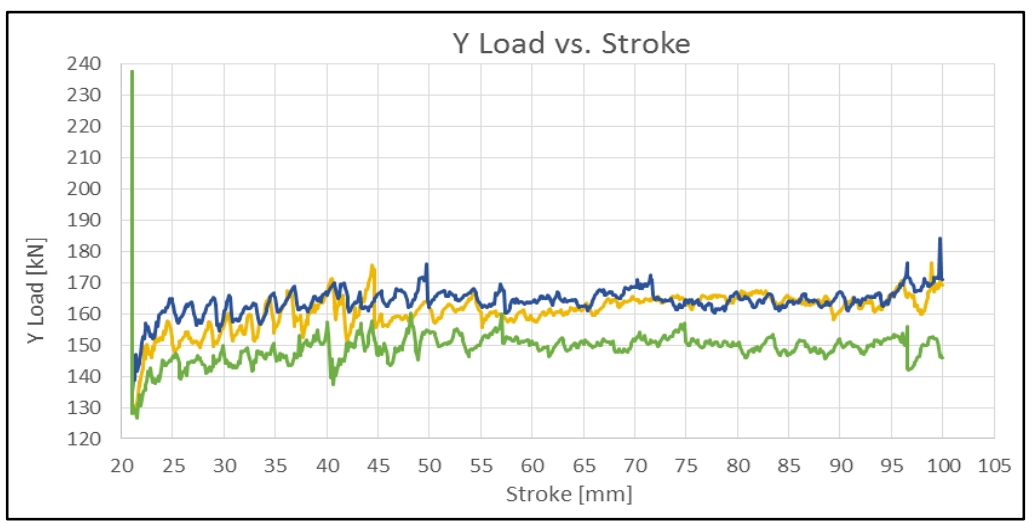

Figure 13: Shapes of the curves - load vs. stroke (yellow - C10; blue-20MnCr5; green -34CrNiMo6).

In the second comprehensive evaluation of obtained results (Fig. 13), the loads are the same as in the previous graph. However, for stroke dependence, these were recorded values indicating the most appropriate material. For the third material a stroke of $24 \mathrm{~mm}$ and a load of $145.18 \mathrm{kN}$ at the first tool entry were recorded. It is below $150 \mathrm{kN}$, which is much lower compared to the first and second test material. These exceed the threshold.

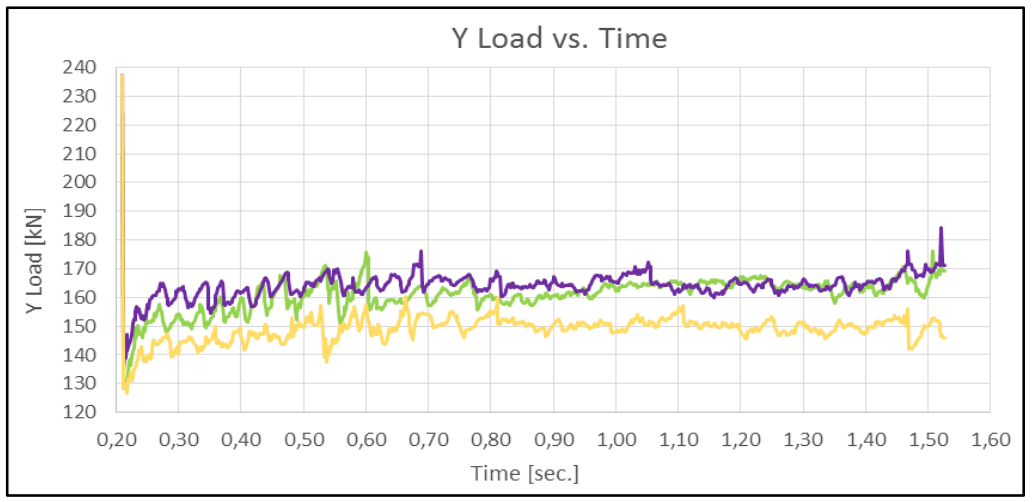

Figure 14: Shapes of the curves - load vs. time (green-C10; purple-20MnCr5; yellow -34CrNiMo6). 
During the third comprehensive evaluation of obtained results (Fig. 14), when the first start of the tool was detected, it was $0.26 \mathrm{sec}$. After the time of 0.8 seconds, the material differences under load were minimal (smallest). The first material at that time had a load of $158 \mathrm{kN}$, the second material had a load of $161 \mathrm{kN}$, and the third material had a load of $155 \mathrm{kN}$.

\section{CONCLUSION}

Obtained results offer information about strength analyses in the Deform-3D simulation software program during the simulation of tube drawing, stresses in the area of diameter reduction, smaller deformations, mechanical but also temperature differences. Described research and obtained results can be used in subsequent research of forming tools for tube productions with inner grooving surface and can be used as reference sample in the area of research of next material types. From a practical point of view, this paper provides complete information about tested materials, which create qualitative background in selection of the most suitable material for drawn grooved tubes. Results of the simulations shows:

- Maximal obtained stress value was $670 \mathrm{MPa}$.

- Maximal temperature on the edge of groove during forming was $118^{\circ} \mathrm{C}$.

- Maximal value of strain was recorded in the groove at value 2.03 compared to $34 \mathrm{MnCr} 5$ at 1.61 .

- Highest value of the load was observed for the material $20 \mathrm{MnCr} 5-181 \mathrm{kN}$.

- Lowest value of the load was observed for the material 34CrNiMo5-136 kN.

- Overall curves of load show that course for 34CrNiMo5 reaches lower values compared to $20 \mathrm{MnCr} 5$ and $\mathrm{C} 10$.

When designing the forming tool, it is also necessary to consider also the lead-in part of the tool. Incorrect geometry can be the cause of "cavitation". These micro-cracks formed during the drawing of the tubes through the die and with the aid of the grooving mandrel, are formed after a time of so-called "cavities" (vacuum bubbles), where a micro-explosion occurs. Such simulations can predict the behaviour of the pipes during the drawing process, thus avoiding various errors and determining early precautions. The result was a comparison of three tested materials, where with the help of the resulting analyses it is possible to determine the most suitable material for drawn grooved tubes.

\section{ACKNOWLEDGEMENT}

This work was supported by the Slovak Research and Development Agency under the contract No. APVV-15-0696. This work was supported by a project VEGA 1/0682/17.

\section{REFERENCES}

[1] Hutyrová, Z.; Harničarová, M.; Zajac, J.; Valíček, J.; Mihok, J. (2013). Experimental study of surface roughness of wood plastic composites after turning, Advanced Materials Research, Vol. 856, 108-112, doi:10.4028/www.scientific.net/AMR.856.108

[2] Jurko, J.; Panda, A.; Behún, M. (2012). Prediction of a new form of the cutting tool according to achieve the desired surface quality, Applied Mechanics and Materials, Vol. 268-270, 473-476, doi:10.4028/www.scientific.net/AMM.268-270.473

[3] Čep, R.; Janásek, A.; Petrů, J.; Sadilek, M.; Mohyla, P.; Valíček, J.; Harničárová, M.; Czán, A. (2013). Surface roughness after machining and influence of feed rate on process, Key Engineering Materials, Vol. 581, 341-347, doi:10.4028/www.scientific.net/KEM.581.341

[4] Peterka, J.; Pokorný, P. (2013). Influence of the lead angle from the vertical axis milling on effective radius of the cutter, Key Engineering Materials, Vol. 581, 44-49, doi:10.4028/www.scientific.net/KEM.581.44 
[5] Baron, P.; Kočiško, M.; Blaško, L.; Szentivanyi, P. (2017). Verification of the operating condition of stationary industrial gearbox through analysis of dynamic signal, measured on the pinion bearing housing, Measurement, Vol. 96, 24-33, doi:10.1016/j.measurement.2016.10.048

[6] Gerin, B.; Pessard, E.; Morel, F.; Verdu, C.; Mary, A. (2015). Effect of cold forming on the high cycle fatigue behaviour of a 27MnCr5 steel, Procedia Engineering, Vol. 133, 603-612, doi:10.1016/j.proeng.2015.12.636

[7] Linardon, C.; Affagard, J.-S.; Chagnon, G.; Favier, D.; Gruez, B. (2011). Simulation of drawing of small stainless-steel platinum medical tubes-influence of the tool parameters on the forming limit, AIP Conference Proceedings, Vol. 1353, No. 1, 431-436, doi:10.1063/1.3589553

[8] Boutenel, F.; Delhomme, M.; Velay, V.; Boman, R. (2018). Finite element modelling of cold drawing for high-precision tubes, Comptes Rendus Mécanique, Vol. 346, No. 8, 665-677, doi:10.1016/j.crme.2018.06.005

[9] Henriksen, J.; Hansen, M. R.; Thrane, F. C. (2017). Axial load capacity of cold formed pipe flange connection, Journal of Pressure Vessel Technology, Vol. 139, No. 5, Paper 051201, 8 pages, doi: $10.1115 / 1.4036853$

[10] Li, Z.; Han, J.; Yu, C.; Zhang, C. (2017). Numerical and experimental investigation on forming stacer using compositing stretch and press bending process, The International Journal of Advanced Manufacturing Technology, Vol. 92, No. 5-8, 2525-2533, doi:10.1007/s00170-017-0340-Z

[11] Biba, N.; Stebunov, S.; Vlasov, A. (2008). Material forming simulation environment based on QForm3D software system, Energy, Vol. 2, No. 4, 6 pages

[12] Reggio, M.; McKenty, F.; Gravel, L.; Cortes, J.; Morales, G.; Ladron de Guevara, M. A. (2002). Computational analysis of the process for manufacturing seamless tubes, Applied Thermal Engineering, Vol. 22, No. 4, 459-470, doi:10.1016/S1359-4311(01)00093-X

[13] Necpal, M.; Martinkovič, M.; Václav, Š. (2018). Determination of the coefficient of friction under cold tube drawing using FEM simulation and drawing force measurement, Research Papers Faculty of Materials Science and Technology Slovak University of Technology, Vol. 26, No. 42, 29-34, doi:10.2478/rput-2018-0003

[14] Necpal, M.; Kapustová, M.; Martinkovič, M. (2020). Using 2D/3D FEM simulation to determine drawing force in cold drawing of steel tubes with straight internal rifling, Solid State Phenomena, Vol. 304, 121-125, doi:10.4028/www.scientific.net/SSP.304.121

[15] Šuták, D.; Hatala, M.; Dilýová, M.; Botko, F.; Poklemba, R. (2020). Reduction of tubes diameter by the die and mandrel in simulation software, TEM Journal, Vol. 9, No. 1, 380-385, doi:10.18421/TEM91-52

[16] Necpal, M.; Martinkovič, M. (2019). Finite element modelling of cold drawing inner finned tube, Proceedings of the $30^{\text {th }}$ DAAAM International Symposium on Intelligent Manufacturing and Automation, 0622-0627, doi:10.2507/30th.daaam.proceedings.085

[17] Krolczyk, G.; Legutko, S.; Nieslony, P.; Gajek, M. (2014). Study of the surface integrity microhardness of austenitic stainless steel after turning, Technical Gazette, Vol. 21, No. 6, 1307 1311

[18] Ridzon, M.; Mojzis, M.; Bella, P.; Parilak, L.; Kan, M.; Buransky, I. (2019). Validation of results of two different reductions for precision seamless cold drawn tubes, Metallurgy, Vol. 58, No. 3-4, 319-322

[19] Butt, A. I. K.; Abbas, M.; Ahmad, W. (2020). A mathematical analysis of an isothermal tube drawing process, Alexandria Engineering Journal, Vol. 59, No. 5, 3419-3429, doi:10.1016/ j.aej.2020.05.021

[20] Russo, R.; Girot Mata, F. A.; Forest, S.; Jacquin, D. (2020). A Review on strain gradient plasticity approaches in simulation of manufacturing processes, Journal of Manufacturing and Materials Processing, Vol. 4, No. 3, Paper 87, 29 pages, doi:10.3390/jmmp4030087

[21] Gusel, L.; Boskovic, V.; Domitner, J.; Ficko, M.; Brezocnik, M. (2018). Genetic programming method for modelling of cup height in deep drawing process, Advances in Production Engineering \& Management, Vol. 13, No. 3, 358-365, doi:10.14743/apem2018.3.296

[22] Domański, T.; Sapietová, A.; Sága, M. (2017). Application of Abaqus software for the modeling of surface progressive hardening, Procedia Engineering, Vol. 177, 64-69, doi:10.1016/j.proeng.2017.02.184 
[23] Khovanskyi, S.; Pavlenko, I.; Pitel, J.; Mizakova, J.; Ochowiak, M.; Grechka, I. (2019). Solving the coupled aerodynamic and thermal problem for modeling the air distribution devices with perforated plates, Energies, Vol. 12, No. 18, Paper 3488, 16 pages, doi:10.3390/en12183488

[24] Dodok, T.; Čuboňová, N.; Císar, M.; Kuric, I.; Zajačko, I. (2017). Utilization of strategies to generate and optimize machining sequences in CAD/CAM, Procedia Engineering, Vol. 192, 113 118, doi:10.1016/j.proeng.2017.06.020

[25] Wan, Q.; Zheng, M. L.; Yang, S. C.; Sun, J. K. (2019). Optimization of micro-texture distribution through finite-element simulation, International Journal of Simulation Modelling, Vol. 18, No. 3, 543-554, doi:10.2507/IJSIMM18(3)CO15

[26] Gusel, L.; Rudolf, R.; Brezocnik, M. (2018). Hardness modelling of deformed CW106C alloy by a genetic programming, International Journal of Simulation Modelling, Vol. 17, No. 2, 210-219, doi:10.2507/IJSIMM17(2)414

[27] Trzepiecinski, T.; Lemu, H. G.; Fejkiel, R. (2017). Numerical simulation of effect of friction directionality on forming of anisotropic sheets, International Journal of Simulation Modelling, Vol. 16, No. 4, 590-602, doi:10.2507/IJSIMM16(4)3.392

[28] Satošek, R.; Valeš, M.; Pepelnjak, T. (2019). Study of influential parameters of the sphere indentation used for the control function of material properties in forming operations, Strojniski vestnik - Journal of Mechanical Engineering, Vol. 65, No. 10, 585-598, doi:10.5545/svjme.2019.6312

[29] Nowotynska, I.; Kut, S.; Osetek, M. (2018). The use of simulation methods in the analysis of the manufacturing process of hex Allen bolts, Technical Gazette, Vol. 25, No. 4, 1213-1218, doi:10.17559/TV-20160728142508

[30] Straka, M.; Hurna, S.; Bozogan, M.; Spirkova, D. (2019). Using continuous simulation for identifying bottlenecks in specific operation, International Journal of Simulation Modelling, Vol. 18, No. 3, 408-419, doi:10.2507/IJSIMM18(3)477

[31] EN 10263-4:2001. Steel rod, bars and wire for cold heading and cold extrusion - Part 4: Technical delivery conditions for steels for quenching and tempering, European Committee for Standardization, Brussels

[32] European Steel and Alloy Grades/Numbers. Steel Numbers, from http://www.steelnumber.com, accessed on 17-09-2020 